\title{
The CXCR4-CXCL12-Axis Is of Prognostic Relevance in DLBCL and Its Antagonists Exert Pro-Apoptotic Effects In Vitro
}

\author{
Katrin Pansy ${ }^{1}{ }^{\circledR}$, Julia Feichtinger ${ }^{2}$, Barbara Ehall ${ }^{1}$, Barbara Uhl ${ }^{1} \oplus$, Miriam Sedej ${ }^{3}$, \\ David Roula $^{3}{ }^{\circledR}$, Beata Pursche ${ }^{1}$, Axel Wolf ${ }^{4}$, Manuel Zoidl ${ }^{5}$, Elisabeth Steinbauer ${ }^{6}$, \\ Verena Gruber ${ }^{6}$, Hildegard T Greinix ${ }^{1}$, Katharina T. Prochazka ${ }^{1}$, Gerhard G. Thallinger ${ }^{7,8} \mathbb{D}^{\circ}$, \\ Akos Heinemann ${ }^{3}{ }^{(D}$, Christine Beham-Schmid ${ }^{6}$, Peter Neumeister ${ }^{1}$, Tanja M. Wrodnigg ${ }^{5}$, \\ Karoline Fechter ${ }^{1,+}$ and Alexander JA. Deutsch ${ }^{1, *,+}$ (D) \\ 1 Division of Hematology, Medical University Graz; Auenbruggerplatz 38, 8036 Graz, Austria; \\ katrin.pansy@medunigraz.at (K.P.); barbara.ehall@medunigraz.at (B.E.); barbara.uhl@medunigraz.at (B.U.); \\ Beata_Prusche@yahoo.de (B.P.); hildegard.greinix@medunigraz.at (H.T.G.); \\ KatharinaTheresa.Prochazka@klinikum-graz.at (K.T.P.); peter.neumeister@medunigraz.at (P.N.); \\ fechterkaroline@gmail.com (K.F.) \\ 2 Division of Cell Biology, Histology and Embryology, Gottfried Schatz Research Center for Cell Signaling, \\ Metabolism and Aging, Medical University of Graz, Neue Stiftingtalstraße 6/II, 8010 Graz, Austria; \\ julia.feichtinger@medunigraz.at \\ 3 Otto Loewi Research Center for Vascular Biology, Immunology and Inflammation, Division of Pharmacology, \\ Medical University of Graz, Universitätsplatz 4/I, 8010 Graz, Austria; miriam.sedej@medunigraz.at (M.S.); \\ david.roula@medunigraz.at (D.R.); akos.heinemann@medunigraz.at (A.H.) \\ 4 Division of General Otorhinolaryngology, Medical University of Graz, Auenbruggerplatz 26, 8036 Graz, \\ Austria; axel.wolf@klinikum-graz.at \\ 5 Institute of Organic Chemistry, Graz University of Technology, Stremayrgasse 9/4, 8010 Graz, Austria; \\ manuel.zoidl@tugraz.at (M.Z.); t.wrodnigg@tugraz.at (T.M.W.) \\ 6 Diagnostic \& Research Institute of Pathology, Medical University Graz, Neue Stiftingtalstraße 6, 8010 Graz, \\ Austria; elisabeth.steinbauer@klinikum-graz.at (E.S.); verena.gruber@klinikum-graz.at (V.G.); \\ christine.beham@medunigraz.at (C.B.-S.) \\ 7 Institute of Computational Biotechnology, Graz University of Technology, Petersgasse 14/V, 8010 Graz, \\ Austria; gerhard.thallinger@tugraz.at \\ 8 OMICS Center Graz, BioTechMed Graz, Stiftingtalstraße 24, 8010 Graz, Austria \\ * Correspondence: alexander.deutsch@medunigraz.at; Tel.: +43-316-385-72816 \\ $\dagger$ These authors contributed equally to this work.
}

Received: 30 July 2019; Accepted: 21 September 2019; Published: 24 September 2019

\begin{abstract}
In tumor cells of more than 20 different cancer types, the CXCR4-CXCL12-axis is involved in multiple key processes including proliferation, survival, migration, invasion, and metastasis. Since data on this axis in diffuse large B cell lymphoma (DLBCL) are inconsistent and limited, we comprehensively studied the CXCR4-CXCL12-axis in our DLBCL cohort as well as the effects of CXCR4 antagonists on lymphoma cell lines in vitro. In DLBCL, we observed a 140-fold higher CXCR4 expression compared to non-neoplastic controls, which was associated with poor clinical outcome. In corresponding bone marrow biopsies, we observed a correlation of CXCL12 expression and lymphoma infiltration rate as well as a reduction of CXCR4 expression in remission of bone marrow involvement after treatment. Additionally, we investigated the effects of three CXCR4 antagonists in vitro. Therefore, we used AMD3100 (Plerixafor), AMD070 (Mavorixafor), and WKI, the niacin derivative of AMD070, which we synthesized. WK1 demonstrated stronger pro-apoptotic effects than AMD070 in vitro and induced expression of pro-apoptotic genes of the BCL2-family in CXCR4-positive lymphoma cell lines. Finally, WK1 treatment resulted in the reduced expression of JNK-, ERK1/2- and NF-KB/BCR-target genes. These data indicate that the CXCR4-CXCL12-axis impacts the pathogenesis of DLBCL and represents a potential therapeutic target in aggressive lymphomas.
\end{abstract}


Keywords: DLBCL 1; CXCR4-CXCL12-axis 2; CXCR4 antagonist 3

\section{Introduction}

Diffuse large B cell lymphoma is an aggressive lymphoid malignancy and represents the most common subtype of non-Hodgkin lymphoma (NHL) in adults [1]. It arises de novo or by transformation of indolent lymphomas such as follicular lymphomas (FL) [2]. Although DLBCL is in many instances a curable disease, around $40 \%$ of patients are refractory or relapse. Based on gene expression profiling, DLBCL can be divided into two different subtypes [3,4]: (i) germinal center B cell-like (GCB-DLBCL), (ii) activated $B$ cell-like (ABC-DLBCL), or in the case of usage of an immunohistochemical algorithm non-germinal center B cell-like (NGCB-DLBCL) [5]. These subtypes are associated with distinctly different overall survival (OS) rates. While GCB-DLBCL patients show favorable overall survival, patients with the NGCB-DLBCL have a worse prognosis [3,4].

The chemokine receptor CXCR4 and its ligand CXCL12 are implicated in the retention of $\mathrm{B}$ cell precursors and B cell homing to lymph nodes, and therefore play an important role in B cell development [6-9]. In solid cancer, abnormalities in the CXCR4-CXCL12-axis have been linked to many processes including proliferation, survival, migration, invasion, and metastasis [10-12], thereby providing evidence for the importance of this chemokine signaling pathway. So far, we and other groups have conducted studies investigating the role of CXCR4 in DLBCL, whereby the results mainly pointed toward a prominent role of CXCR4 in lymphoma dissemination [10-16]. However, the data from these studies are to some extent inconsistent and limited, and in particular, combined analyses on CXCR4, CXCL12, and CXCR7, also known to bind CXCL12 [17], are scarce.

Therefore, we aimed to comprehensively study CXCR4, CXCL12, and CXCR7 expression in the DLBCLs samples and corresponding non-neoplastic bone marrow (BM) samples as well as to determine the in vitro effect of two commercially available CXCR4 antagonists, namely AMD3100 and AMD070 [18], and a niacin derivative of AMD070 called WK1, which was generated by us. Hence, we showed that CXCR4 was higher expressed in DLBCL and that a high CXCR4 expression was associated with reduced survival. We also demonstrated that CXCL12 expression correlated to the BM infiltration rate and that CXCR4 was lower expressed in BM samples from patients exhibiting a remission of lymphoma infiltration after therapy. Both WK1 and AMD070 showed pro-apoptotic effects, which were especially more pronounced in the CXCR4+ lymphoma cell lines treated with WK1. Collectively, our results indicate an impact of the CXCR4-CXCL12-axis on lymphomagenesis and its potential role as a therapeutic target.

\section{Results}

\subsection{High Expression of CXCR4 Is Associated with Poor Clinical Outcome in DLBCL}

We determined the expression levels of CXCR4, CXCR7, and their ligand CXCL12 [19] in NGCBand GCB-DLCBLs consisting of primary and transformed follicular lymphomas ( $n=71$ in total) and germinal center $\mathrm{B}$ cells (GC-B, $n=5$ ) serving as non-neoplastic controls by using RQ-PCR. We observed an average of 140-fold higher CXCR4 expression in DLBCL and all investigated DLBCL subgroups in comparison to the GC-Bs (Figure 1a, $p<0.001$ ), whereas no differential expression was found for CXCR7 and CXCL12 (Figure 1a and Figure S1a). Furthermore, we observed a 4.7-fold higher CXCR4 expression in lymphomas with an advanced stage (stage 2-4) compared to DLBCL patients with clinical stage 1 (Figure 1b, $p=0.028$ ). BM infiltrating DLBCL displayed a 3.1-fold higher CXCR4 expression (Figure $1 \mathrm{~b}, p=0.023$ ). Additionally, a positive correlation of CXCR4 expression and BM infiltration was observed (Spearman rho $=0.550$ and $p<0.001$, Figure 1b). In contrast, no association was found for CXCL12 and CXCR7 (Figure $1 b$ and Figure S1b). 
a
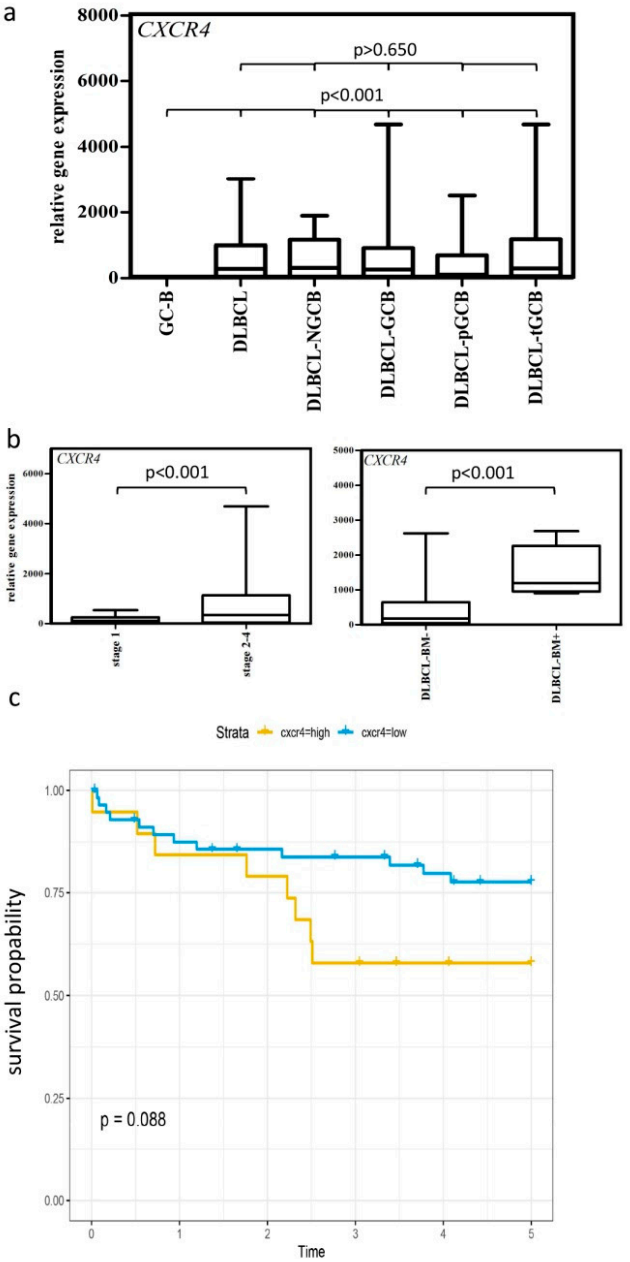

d
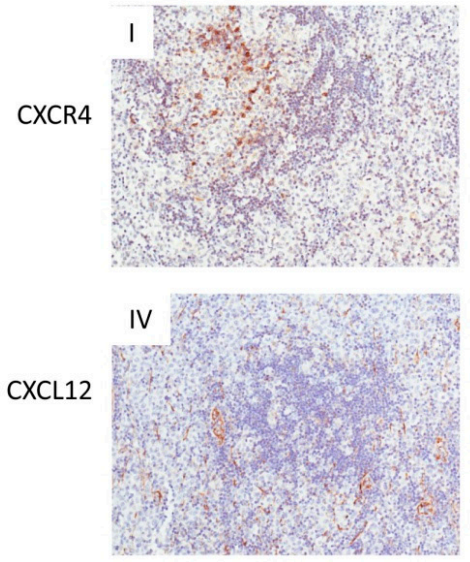
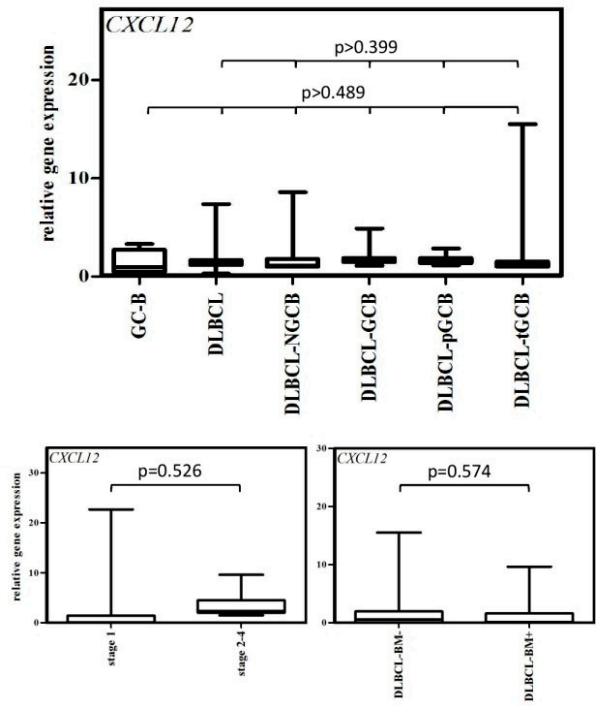

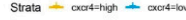
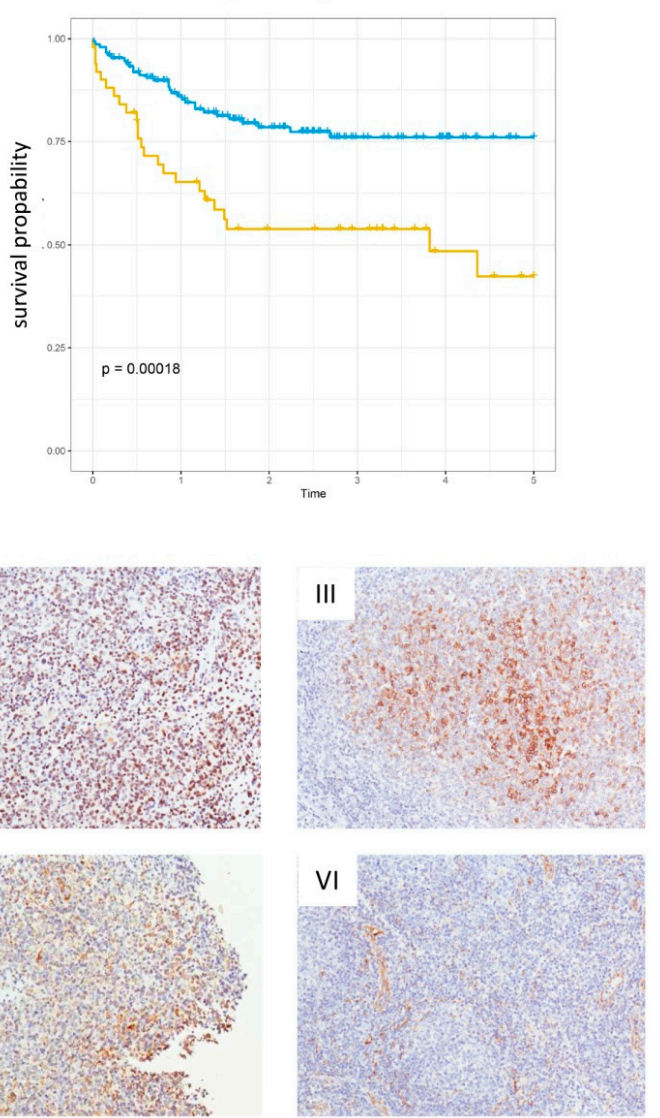

Figure 1. CXCR4 and CXCL12 expression in DLBCL. (a) Expression analysis of CXCR4 and CXCL12 in non-neoplastic control germinal center B cells (GC-B) and diffuse large B cell lymphoma cells (DLBCL) consisting of DLBCL-NGCB and DLCBL-GCB, by RQ-PCR. GCB-DLBCL were further subdivided into primary (DLBCL-pGCB) and transformed DLBCL (DLBCL-pGCB) originating from follicular lymphoma. (b) Expression analysis of CXCR4 and CXCL12 in DLBCL samples with early (stage 1) and advanced stage (stage 2-4) (left graphs) and DLBCL samples with and without bone marrow infiltration (right graphs) by RQ-PCR. (c) Probability of 5-year-survival in DLBCL patients (our cohort left panel and the cohort of Lenz et al. right [20]) stratified by the third quartile of CXCR4 expression, respectively. (d) Representative immunohistochemical stains of CXCR4 (I-III) and CXCL12 (IV-VI) on DLBCL samples (magnification 20×). mRNA expression levels were calculated as a relative expression in comparison to the GC-B cells. All images were captured using an Olympus BX51 microscope and an Olympus E-330 camera. 
By dividing the patients into two groups using the third quartile of CXCR4 mRNA expression, a tendency for an association between high CXCR4 expression and a poor 5-year-survival rate was observed in our cohort ( $p=0.088$, log-rank test, Figure 1c). Focusing on de novo DLBCL cases, we obtained similar results ( $p=0.051$, log-rank test, Figure S2a). This tendency could be confirmed in a public microarray DLBCL dataset [20] ( $p=0.00018, \log$-rank test, Figure 1c). For CXCR7 and CXCL12 mRNA expression, no association was observed either for the whole lymphoma cohort or for the de novo group (Figure S2b-e).

To determine whether high CXCR4 and CXCL12 mRNA expression translated into high protein levels, immunohistochemical analysis for CXCR4 and CXCL12 was performed on the DLBCL samples (Figure 1d, $n=40$ ), for which enough material was left. CXCR7 was excluded from further analysis based on its expression profile. For CXCR4 and CXCL12, a significant positive correlation was detected (Spearman rho $=0.714$ for CXCR4 and Spearman rho $=0.694$ for CXCL12, $p<0.01)$. Additionally, we observed that CXCR4 was exclusively expressed on lymphoma cells (on average $64.5 \%$ of lymphoma cells), whereas CXCL12 (on average 30.3\% of lymphoma cells) was mainly expressed by lymphoma cells, but was also present in the microenvironment (reactive immune cells and endothelial cells).

\subsection{CXCR4 Is Somatically Unmutated in DLCBL}

Since mutations in the CXCR4 coding sequence frequently occur in B cell lymphomas [21,22], direct sequence analysis was performed on lymphoma samples $(n=25)$ and in lymphoma cells lines $(n=4)$. We could detect a single-nucleotide polymorphism (rs2228014), which had previously been described and derived from publicly available databases [23]. rs2228014, located in exon 2, was found in three of the 25 investigated DLBCL samples and in one of the four investigated cell lines (U2932). Apart from rs2228014, no other alterations were detected (Table 1).

Table 1. Single nucleotide polymorphism occurring in the CDS of CXCR4 in our DLBCL cohort and investigated lymphoma cell lines.

\begin{tabular}{|c|c|c|c|c|}
\hline ID & Type & & CXCR4 Exon1 & CXCR4 Exon2 \\
\hline Al1 & ngcb & & WT & WT \\
\hline $\mathrm{Al} 2$ & $\mathrm{gcb}$ & transformed & WT & WT \\
\hline $\mathrm{Al} 3$ & $\mathrm{gcb}$ & transformed & WT & rs2228014 \\
\hline Al4 & $\mathrm{gcb}$ & transformed & WT & WT \\
\hline Al5 & ngcb & & WT & WT \\
\hline Al6 & $\mathrm{gcb}$ & & WT & WT \\
\hline Al8 & $\mathrm{gcb}$ & transformed & WT & WT \\
\hline Al9 & $\mathrm{gcb}$ & & WT & WT \\
\hline Al10 & ngcb & & WT & WT \\
\hline Al11 & $\mathrm{ngcb}$ & & WT & rs2228014 \\
\hline Al12 & ngcb & & WT & WT \\
\hline Al13 & $\mathrm{ngcb}$ & & WT & WT \\
\hline Al14 & $\mathrm{gcb}$ & transformed & WT & WT \\
\hline Al16 & $\mathrm{gcb}$ & transformed & WT & WT \\
\hline Al17 & $\mathrm{gcb}$ & transformed & WT & WT \\
\hline Al18 & $\mathrm{gcb}$ & & WT & WT \\
\hline Al19 & $\mathrm{gcb}$ & transformed & WT & WT \\
\hline $\mathrm{A} 120$ & $\mathrm{gcb}$ & transformed & WT & WT \\
\hline $\mathrm{Al} 21$ & ngcb & & WT & WT \\
\hline $\mathrm{Al} 22$ & $\mathrm{gcb}$ & & WT & rs2228014 \\
\hline $\mathrm{Al} 26$ & $\mathrm{gcb}$ & transformed & WT & WT \\
\hline $\mathrm{Al} 28$ & $\mathrm{gcb}$ & transformed & WT & WT \\
\hline $\mathrm{Al} 33$ & ngcb & & WT & WT \\
\hline $\mathrm{Al} 34$ & $\mathrm{gcb}$ & transformed & WT & WT \\
\hline Al71 & ngcb & & WT & WT \\
\hline BL2 & cell line & Burkitt like & WT & WT \\
\hline SuDHl4 & cell line & GCB like & WT & WT \\
\hline RI1 & cell line & NGCB like & WT & WT \\
\hline U2932 & cell line & NGCB like & WT & rs2228014 \\
\hline
\end{tabular}

WT denotes unmutated. 


\subsection{CXCR4-CXCL12-Axis Is Associated with Bone Marrow Infiltration in DLBCL}

To further investigate the role of the CXCR4-CXCL12-axis in BM infiltration by aggressive lymphomas, we performed RQ-PCR analysis on the corresponding BM biopsies in our lymphoma cohort. In total, $63 \mathrm{BM}$ specimens were used: 52 bone marrow samples were taken at time of diagnosis including 12 patients with BM infiltration at time of diagnosis. From 11 patients, repeated biopsies were taken during their course of disease. Of those, seven patients went into remission while four patients relapsed.

Comparison of CXCR4 and CXCL12 mRNA expression levels in BM specimens with and without lymphoma infiltration at time of diagnosis showed a 1.6-fold higher CXCR4 expression in BM specimens exhibiting lymphoma infiltration (Figure $2 \mathrm{a}, p=0.008$ ). In contrast, no statistically significant difference was detected for CXCL12 (Figure 2a, $p=0.663$ ). However, we observed a strong positive correlation between CXCL12 expression and percentage of infiltration rate in the investigated BM biopsies (Spearman rho $=0.764, p=0.001$ ).

Furthermore, we analyzed the CXCR4 and CXCL12 mRNA expression in seven paired BM samples of previously infiltrated BMs losing infiltration following chemotherapy (BM under remission). Loss of $\mathrm{BM}$ infiltration led to a 3.2-fold reduction of CXCR4 expression (Figure $2 \mathrm{~b}, p=0.032$ ), whereas no significant difference was detected for CXCL12 (Figure $2 b, p=0.382$ ).

Immunohistochemical analysis of CXCR4 and CXCL12 on selected BM specimens $(n=19)$ additionally confirmed the mRNA data. We observed a moderate positive correlation between BM infiltration and protein abundance for both markers (Figure 2c, Spearman rho $=0.595, p=0.031$ for CXCR4 and Spearman rho $=0.775, p=0.005$ for CXCL12). Interestingly, we detected that in the infiltrated BM samples, an average of $80 \%$ of lymphoma cells expressed CXCR4 and an average of $35 \%$ of them expressed CXCL12, whereas in the surrounding tissue (stroma) as well as in the BM samples without involvement, less than $30 \%$ of the stroma cells expressed CXCR4 and CXCL12 (Figure 2c I-IV).
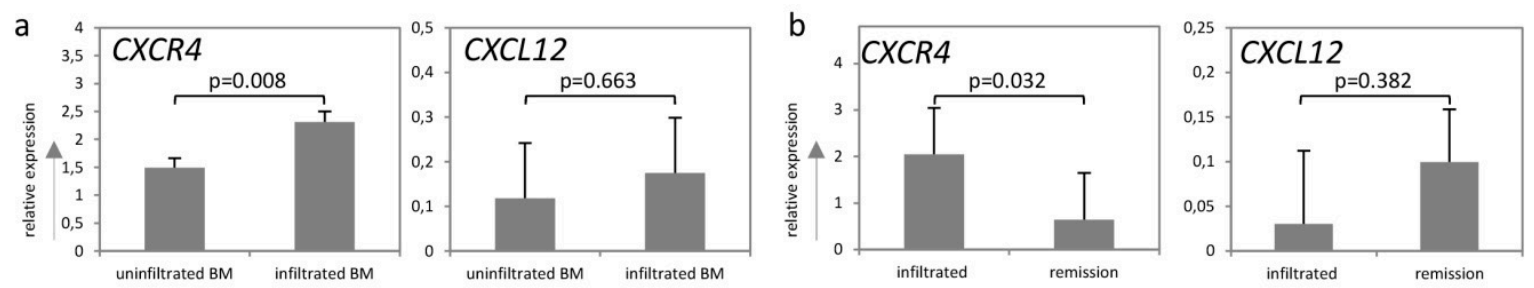

C

CXCR4

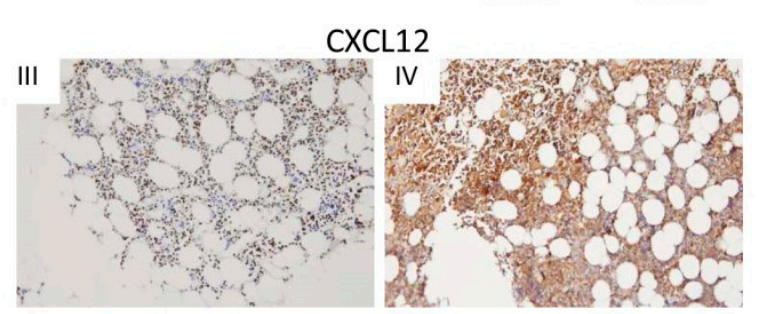

Figure 2. CXCR4 and CXCL12 expression and BM infiltration. (a) Expression analysis of CXCR4 and CXCL12 in uninfiltrated and infiltrated bone marrow specimens at the time of diagnosis by RQ-PCR. (b) Expression analysis of CXCR4 and CXCL12 in infiltrated bone marrow biopsies and the respective paired sample in patients under remission by RQ-PCR. (c) Representative immunohistochemical stains of CXCR4 (I-II) and CXCL12 (III-IV) on selected bone marrow specimens of DLBCL patients (magnification 20×). (I) and (III) represent the CXCR4 and CXCL12 staining of uninfiltrated bone marrow specimens, and (II) and (IV) represent those of the infiltrated bone marrow specimens. mRNA expression levels were calculated as a relative expression in comparison to uninfiltrated bone marrow specimens. Each bar represents the mean values of expression levels \pm standard error of the mean (SEM). The comparison of the expression levels was performed by using the Mann-Whitney U-test or the Student's t-test. All images were captured using an Olympus BX51 microscope and an Olympus E-330 camera. 


\subsection{Treatment of Lymphoma Cell Lines with CXCR4 Antagonists Induced Apoptosis}

To investigate the effects of CXCR4-antagonists in vitro, we used the following cell lines: SuDHL4 (as a GCB-DLBCL model), and RI-1 and U2932 (as a NGCB-DLBCL model). Additionally, the lymphoma cell line BL2, which is known to strongly express CXCR4 and to migrate toward CXCL12 in transwell migration assays [24], was included.

First, we characterized the surface expression of CXCR4 in all four investigated cell lines by flow cytometry followed by the CXCL12 ${ }^{\mathrm{AF} 647}$ binding assay combined with blocking antibodies for CXCR4 and CXCR7. CXCR4 expression was found for the BL2, RI-1, SuDHL4, and U2932 cell lines, respectively (Figure S3a). Furthermore, we observed that CXCL12AF ${ }^{647}$ was bound just via CXCR4 in the BL2, SuDHL4, and U2932 cells, whereas it was additionally bound via CXCR7 in the RI-1 cells, indicating that these two cell lymphoma lines also express CXCR7 on their surface (Figure S3b).

Next, the in vitro effect of the three CXCR4 antagonists (Figure 3a)-AMD3100 (FDA approved), AMD070 and the niacin derivative of AMD070 (termed WK1, synthesized by us)—were investigated. All three antagonists were able to inhibit CXCL12 ${ }^{\mathrm{AF} 647}$ binding in a concentration-dependent manner as demonstrated by the binding assay on BL2 cells (Figure S4). Furthermore, AMD070 inhibited the Transwell migration of BL2 and U2932 cells, while WK1 showed an inhibitory effect only on U2932 cells (Figure S5). Generally, the effects of WK1 were considerably reduced compared to the other two inhibitors in both the above-described assays (Figures S4 and S5). Interestingly, we observed reduced growth for AMD070 and WK1 in the BL2 and SuDHL4 cells, respectively, whereas the growth rates of all other investigated cell lines were not affected (Figure 3b). Importantly, AMD3100 and niacin alone did not show any effects (Figure $3 \mathrm{~b}$ ). The $\mathrm{IC}_{50}$ values of WK1 were lower compared to those of AMD070 $\left(\mathrm{IC}_{50}=15.4 \mu \mathrm{M}\right.$ in BL2 and $26.76 \mu \mathrm{M}$ in SuDHL4 cells for WK1 vs. $\mathrm{IC}_{50}=31.18 \mu \mathrm{M}$ in BL2 and $26.76 \mu \mathrm{M}$ SuDHL4 cells, Figure 3b). To validate these findings, we treated all four lymphoma cell lines with the three CXCR4 antagonists at concentrations of $1 \mu \mathrm{M}, 5 \mu \mathrm{M}, 10 \mu \mathrm{M}, 20 \mu \mathrm{M}$, and $40 \mu \mathrm{M}$. We observed that the percentage of Annexin V+ cells in BL2 and SuDHL4 was significantly increased after four treatments with AMD070 and WK1 at $40 \mu \mathrm{M}$ compared to AMD3100 and DMSO (Figure $3 c, p<0.005$ ), indicating the pro-apoptotic effects of both CXCR4 antagonists. Furthermore, the percentage of viable lymphoma cells, Annexin V-/7AAD-, was reduced in BL2 and SuDHL4 when treated with WK1 with concentrations of $10 \mu \mathrm{M}, 20 \mu \mathrm{M}$, and $40 \mu \mathrm{M}$ compared to DMSO and AMD3100 (Figure S6, $p<0.01$ ). All other investigated cell lines were unaffected by the three different CXCR4 antagonists. Based on the fact that all of the used lymphoma cell lines overexpressed BCL2 [25-28] as shown in Table S1, it seems that the pro-apoptotic effects of AMD070 and WK1 are not influenced by its expression levels.

Finally, we determined the percentage of cells exhibiting cleaved caspase 3 upon DMSO, AMD070, or WK1 treatment of BL2 and SuDHL4 to confirm the pro-apoptotic effects of both antagonists. In both cell lines, two treatments with AMD070 und WK1 resulted in a significantly higher percentage of lymphoma cells staining positive for cleaved caspase 3 (Figure $3 \mathrm{~d}, p<0.01$ ). Remarkably, the percentage of cleaved caspase 3 was significantly higher upon WK1 treatment even at lower concentrations when compared to AMD070 (Figure 3d, $p<0.005$ ). Taken together, this suggests that the novel CXCR4-WK1 antagonism leads to strong pro-apoptotic effects on certain lymphoma cell lines. 
a
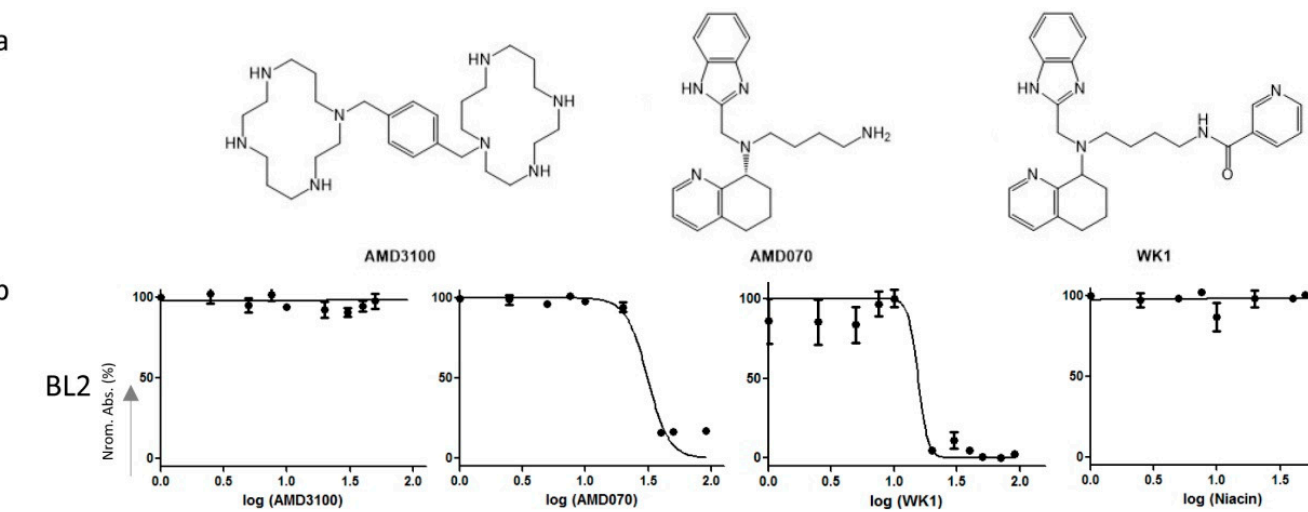

MD3100

AMD070

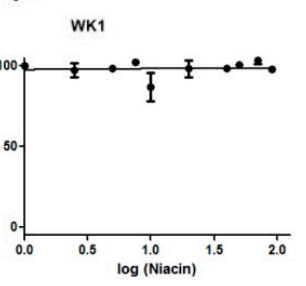

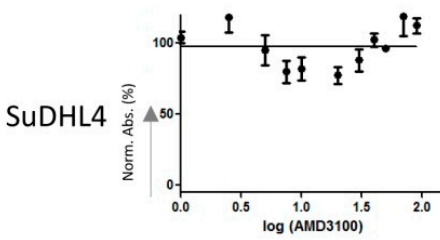
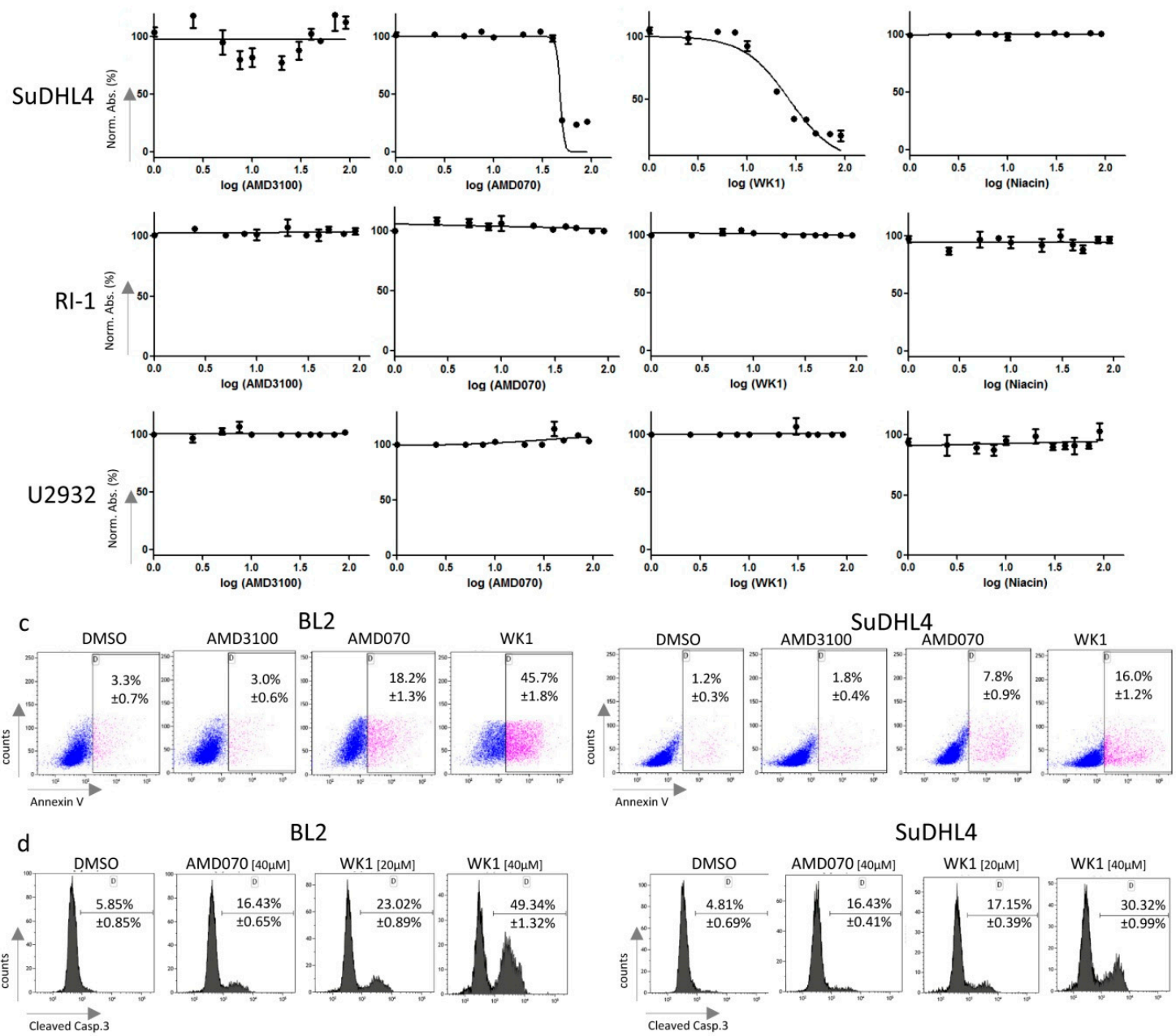

Figure 3. Growth inhibition and apoptosis of B cell lymphoma cell lines upon treatment with CXCR4 antagonists. (a) Structure of the CXCR4 antagonists AMD3100, AMD070, and WK1. (b) Cell growth of SuDHL4 (as GCB-DLBCL model), RI-1 and U2932 (as NGCB-DLBCL model), and BL2 (as Burkitt model) cell lines in the presence of increasing concentrations (range: 1-90 $\mu \mathrm{M}$ ) of the CXCR4 antagonists AMD3100, AMD070, its niacin derivative WK1 and niacin, respectively, as determined by the EZ4U proliferation assay and expressed by percentage of normal absorption. (c) Annexin V positivity of BL2 (as Burkitt model) and SuDHL4 (as GCB-DLBCL model) cells treated with AMD3100, AMD070 and its niacin derivative WK1 (concentration: $40 \mu \mathrm{M}$; for $48 \mathrm{~h}$ ) as determined by flow cytometry and compared to the DMSO treated control cells. The treatments and Annexin V staining were performed in triplicate and the medians \pm standard deviations are depicted. (d) Percentage of cleaved caspase 3 positive BL2 (as Burkitt model) and SuDHL4 (as GCB-DLBCL model) cells treated with $40 \mu \mathrm{M}$ of AMD070 or $20 \mu \mathrm{M}$ and $40 \mu \mathrm{M}$ of its niacin derivative WK1 for $24 \mathrm{~h}$ as determined by flow cytometry and compared to the DMSO treated control cells. The treatments and cleaved caspase staining were performed in triplicate and the medians \pm standard deviations are depicted. 


\subsection{WK1 and AMD070 Increased Expression of Pro-Apoptotic BCL2-Members}

To further dissect the pro-apoptotic effects of the three CXCR4 antagonists, we treated BL2 cells, where apoptosis was induced upon incubation with AMD070 and WK1, respectively, and the U2932 cell line, which was unaffected upon treatment, and determined the gene expression levels of pro- and anti-apoptotic members of the BCL2 family.

In BL2 cells, AMD070 treatment when compared to DMSO resulted in the induction of mRNA expression in two of the eight investigated pro-apoptotic genes (Figure S7a I), namely BAK (2.4-fold after $1 \mathrm{~h}, p=0.025)$ and NOXA (3.3-fold after $6 \mathrm{~h}, p=0.03)$. Furthermore, two out of three investigated anti-apoptotic genes (Figure S7a II), namely BCL-XL (4.8-fold after $3 \mathrm{~h}, p=0.039)$ and MCL-1 (3.4-fold after $6 \mathrm{~h}$ and 3.7-fold after $12 \mathrm{~h}, p<0.031$ ) were overexpressed when compared to DMSO. Additionally, AMD070 treatment caused the reduced expression of three pro-apoptotic genes (Figure S7a I), namely BID (5.2-fold after $6 \mathrm{~h}, p=0.032)$, PUMA (2.3-fold after $6 \mathrm{~h}, p=0.042$ ) and the BIM isoform 9 (3.1-fold after $12 \mathrm{~h}, p=0.049$ ). In stark contrast, AMD070 treatment of U2932 cells induced expression (at least 2-fold) of five of the eight investigated pro-apoptotic members of BCL2 family members (Figure S7b I), namely $B A X(2.7$-fold after $1 \mathrm{~h}, p=0.014), N O X A$ (5.3-fold after $6 \mathrm{~h}, p=0.043)$, BID (2-fold after $12 \mathrm{~h}$, $p=0.048)$, BIK (6-fold after $6 \mathrm{~h}, p=0.015)$, and the BIM isoform 9 (2.2-fold after $12 \mathrm{~h}, p=0.046)$ as well as one of three investigated anti-apoptotic BL2 family members, namely BCL-XL (3.7-fold after $1 \mathrm{~h}$, $p=0.044$, Figure S7b II). Furthermore, reduced expression of three pro-apoptotic members (Figure S7b I), BAK (3.7-fold after $1 \mathrm{~h}, p=0.018), B M F$ (3-fold after $1 \mathrm{~h}, p=0.043$ ) and PUMA (2.21-fold after $1 \mathrm{~h}$, $p=0.035)$, was observed.

In BL2 cells, the expression levels of seven of the eight investigated pro-apoptotic genes were at least 2-fold induced by WK1 treatment when compared to the DMSO control $(p<0.05$, Figure S7a I), namely, $B A K$ (3.4-fold after $1 \mathrm{~h}, p=0.006)$, BIM isoform 9 (2.4-fold after $1 \mathrm{~h} p=0.011)$, BIK (3.4-fold after $3 \mathrm{~h}, p=0.041), B M F(11.2$-fold after $3 \mathrm{~h}$ and 3.6-fold after $6 \mathrm{~h}, p<0.041), N O X A(4,2$-fold after $3 \mathrm{~h}$ and 3.9-fold after $12 \mathrm{~h}, p<0.041), B A X$ (33.1-fold after $12 \mathrm{~h}, p=0.029)$, PUMA (2.4-fold, $p=0.023$ ), and $B C L-X L$ (4.1-fold after $12 \mathrm{~h}, p<0.0001$, Figure S7a II) as the anti-apoptotic gene. In contrast to the BL2 cells, WK1 treatment in U2932 cells (Figure S7b I and II) caused at least a 2-fold higher expression of BID (2.1-fold after $12 \mathrm{~h}, p=0.042)$ and BIK (7.8-fold after $6 \mathrm{~h}, p=0.04)$ as pro-apoptotic genes, a 2-fold lower expression of $M C L-1$ (3-fold after $6 \mathrm{~h}, p=0.04$ ) and $B C L-X L(4.1$-fold after $12 \mathrm{~h}, p=0.041)$ as anti-apoptotic genes, and a lower expression of $B A K(3.5$-fold after $1 \mathrm{~h}, p=0.02)$ as a pro-apoptotic BCL2 family member.

Comparing WK1 treated BL2 cells to AMD070, five of the eight investigated pro-apoptotic genes (Figure S7a I, $p<0.043$ ), namely BIK (2.1-fold after $3 \mathrm{~h}$ and 4-fold after $6 \mathrm{~h}, p<0.043), B M F$ (2.4-fold after $3 \mathrm{~h}, p=0.027), B A X$ (33.9-fold after $12 \mathrm{~h}, p=0.028)$, the BIM isoform 9 (3.4-fold after $12 \mathrm{~h}, p=0.011$ ), NOXA (3.8-fold after $12 \mathrm{~h}, p=0.034)$, PUMA (3.8-fold after $12 \mathrm{~h}, p=0.025)$, and BCL-2 (2.4-fold after $6 \mathrm{~h}$, $p=0.044$, Figure S7a II) as one of the three investigated anti-apoptotic genes were higher expressed in the WK1 treated cells. In contrast, WK1 treated U2932 cells exhibited an at least 2-fold lower expression of four of the eight investigated apoptotic genes (Figure S7b I and II), namely BMF (2.4-fold after 6 $\mathrm{h}, p=0.045), N O X A$ (3.4-fold after $6 \mathrm{~h}, p=0.043), B C L-X L(2.4$-fold after $12 \mathrm{~h}, p<0.001)$, and $M C L-1$ (2.4-fold after $6 \mathrm{~h}, p=0.044)$.

AMD3100 treatment of BL2 cells (Figure S8a II) caused an at least 2-fold increase of the expression of the anti-apoptotic $M C L-1$ gene (6.4-fold after $1 \mathrm{~h}, p=0.009)$ and reduced expression of two pro-apoptotic BCL2 family members (Figure S8a I), namely BID (2.4-fold after $6 \mathrm{~h}, p=0.032)$ and PUMA (2.1-fold after $6 \mathrm{~h}$ and 3.3-fold after $12 \mathrm{~h}, p<0.031$ ). In U2932, AMD3100 treatment caused an at least 2-fold lower expression of three of the eight investigated pro-apoptotic genes (Figure S8b I), $p<0.031$ ), namely $B A K$ (2-fold after $1 \mathrm{~h}, p=0.031)$, BIM isoform 9 (2.2-fold after $1 \mathrm{~h}, p=0.0286)$, and BMF (4.8-fold after $1 \mathrm{~h}$, $p<0.001$ ), and a higher expression of the anti-apoptotic gene (Figure S8b II) BCL-XL (3.2-fold after 12 $\mathrm{h}, p=0.008)$. 


\subsection{WK1 Treatment Causes Downregulation of JNK-, ERK1/2, and NF- $\kappa B / B C R$-Targets}

To assess whether treatment with CXCR4 antagonists had any effects on three important pathways known to be implicated in lymphomagenesis [29-33], we treated BL2 cells, where apoptosis was induced upon incubation with AMD070 and WK1, respectively, and the U2932 cell line, which was unaffected upon treatment, and determined the mRNA expression levels of target genes of the c-Jun N-terminal kinases (JNK) - (CCR7, IL-10, CFLAR, ADARB, CCL22 and FN (based on the Ingenuity Pathway Analysis tool)), extracellular signal-regulated kinases (1/2) (ERK1/2)—(cFOS, BUB1, MXD1, JUNB, cJUN, ETV5 and DUSP1 [34]) and nuclear factor kappa-light-chain-enhancer of activated B cells (NF-KB)/B cell receptor (BCR) pathway (RGS1, KLF10, TNF, BCL2A1, OAS1, and CCL4 [35]) in an explorative manner after $24 \mathrm{~h}$.

In BL2 cells, AMD070 treatment caused a reduced expression of BUB1 (2-fold, $p=0.0115$, Figure S9a)—one ERK1/2 targets—and EGR3 (1.6-fold, $p=0.0164$, Figure S9a), a NF-kB/ BCR-target, and a higher expression of MXD1 (1.6-fold, $p=0.0343$, Figure S9a), a ERK1/2 target, and RGS1 (1.6-fold, $p=0.0343$, Figure S9a), a NF-kB/ BCR-target. In stark contrast, WK1-treatment caused loss or lower expression of three of six investigated JNK targets (Figure S9a), namely the loss of $I L-10(p=0.021)$ and lower expression of CFLAR (4.8-fold, $p=0.0226$ ) and ADARB (9.9-fold, $p=0.0001$ ), lower expression of four of seven investigated ERK1/2 targets (Figure S9a), namely BUB1 (95.3-fold, $p=0.0045$ ), MXD1 (12.6-fold, $p=0.0355)$, JUNB (4.8-fold, $p=0.0079)$, and DUSP1 (13.7-fold, $p=0.0275$ ) and lower or higher expression of five of seven NF-kB/BCR-targets (Figure S9a), namely lower expression of EGR3 (27.9-fold, $p=0.0215), B C L 2 A 1$ (5.3-fold, $p=0.044)$, OAS1 (16.3-fold, $p=0.029)$ and CCL4 (4.3 fold, $p=0.0034)$ and higher expression of TNF (6.4-fold, $p=0.042$ ). AMD3100 treatment did not affect the expression levels of any investigated genes. Comparing WK1 treated BL2 cells to AMD070, three ERK1/2 targets, namely BUB1 (46.5-fold, $p=0.001$ ), MXD1 (20.8-fold, $p=0.028$ ), and DUSP1 (22.8-fold, $p=0.038$ ) and four NF-KB/ BCR-targets, namely RGS1 (9.8-fold, $p=0.026$ ), EGR3 (18.3-fold, $p=0.035$ ), BCL2A1 (8.4-fold, $p=0.014$ ), and CCL4 (6-fold, $p=0.003$ ) were lower expressed upon WK1 treatment (Figure S9a).

In U2932 cells, AMD070 treatment (Figure S9b) caused a lower expression of two ERK1/2 targets, namely BUB1 (1.7-fold, $p=0.048$ ) and DUSP1 (2.5-fold, $p=0.019)$, and RGS1 (1.3-fold, $p=0.042$ ), a NF- $\mathrm{KB}$ / BCR-target, and higher expression of MXD1 (1.7-fold, $p=0.049)$. WK1 treatment (Figure S9b) caused a higher expression of FN1 (4.4-fold, $p=0.0097$ ) and ADARB (3-fold, $p=0.008$ ) as the JNK-target, MXD1 (1.7-fold, $p=0.0135$ ) as the ERK1/2 target; and RGS1 (1.3-fold, $p=0.045), E G R 3$ (17-fold, $p=0.0452)$, and TNF (13.7-fold, $p=0.044)$ as the three NF-kB/BCR-targets. Comparing WK1 treated U2932 cells to AMD070 (Figure S9b), higher expression of IL-10 (1.4-fold, $p=0.0132$ ), FN1 (3.7-fold, $p=0.0217)$; two JNK-targets, MXD1 (1.4-fold, $p=0.0095), c J U N(2.1$-fold, $p=0.025)$, cFOS (1.6-fold, $p=0,05)$; and three ERK1/2 targets, RGS1 (1.7-fold, $p=0.0349$ ), EGR2 (2.1-fold, $p=0.025)$, and TNF (3.2-fold, 0.0278) was detected in WK1 treated cells.

\section{Discussion}

This study was designed to comprehensively investigate the expression of the chemokine receptors CXCR4, CXCR7, and their ligand CXCL12 $[9,17,36]$ in DLBCL. For all three genes, their implication in cancer surveillance has been demonstrated in more than 20 different solid cancer types [37-39]. Their role has also been investigated in DLBCL [10-16], however, these data are inconsistent and rather limited. Although we used a small number $(n=5)$ of control samples (GC-B cells), we observed CXCR4 expression in non-neoplastic GC-B cells, but significantly higher expression in DLBCL. By comparing de novo to transformed DLBCL, we did not find any difference, suggesting a similar function of CXCR4 in both groups. Additionally, we detected higher CXCR4 expression in DLBCL exhibiting an advanced disease stage. Our data confirmed other studies, which demonstrated decreased CXCR4 expression for subsets of germinal center B cells and higher expression in DLBCL as well as for patients with advanced-stage disease $[10,12,15,40]$. However, our analysis revealed that high CXCR4 expression was not associated with the NGCB-DLBCL subtype, which was indeed observed by Moreno et al. [14], but contradicts previously published data [10]. This discrepancy might be caused by different applied 
algorithms, which we and others used for NGCB- and GCB-DLBCL classification as well as differences in the DLBCL cohorts. The majority of the included GCB-DLBCL cases in our cohort had been transformed from follicular lymphomas. The distinct genetic and epigenetic alterations of such disease type [41] might, at least partially, explain the observed differences.

In contrast to Moreno et al. [42], who described CXCR7 as a prognostic factor associated with better clinical outcome especially in CXCR4+ DLBCLs, we did not observe any statistically significant association to survival in our cohort. This might be once more caused by differences in the two lymphoma cohorts, since we included a high number of transformed follicular lymphomas in our analysis.

In this study, we observed that CXCL12 is expressed by lymphoma cells and the DLBCL microenvironment. To the best of our knowledge, a comprehensive study on CXCL12 expression in DLCBL has not been performed thus far. Based on our finding that CXCR4 and CXCL12 are expressed simultaneously on lymphoma cells, it might be speculated that an autocrine stimulation loop occurs in aggressive lymphomas.

Survival analysis revealed a trend for high CXCR4 expression associated with poor survival, in concordance with the findings of two other research groups $[13,14,20]$. Together with the fact that CXCR4-CXCL12 signaling activates several pathways like Janus kinases-signal transducer and activator of transcription (JAK-STAT), phosphoinositide 3-kinase (PI3K), protein kinase B (PKB, AKT), mitogen-activated protein kinase (MAPK), and NF-KB [43-45], we hypothesize that the high co-occurrence of the receptor and its ligand influences the resistance of lymphomas toward anti-lymphoma therapy. Hence, we expect that low or even no CXCR4 expression leads to none or low activation of the mentioned pathways, thus leading to a higher therapeutic sensitivity of the lymphoma cells. The study of Laursen et al. [13] demonstrated the growth-inhibitory effects of rituximab, a monoclonal antibody, which is used as a standard therapy to treat DLCBL [46], increased by AMD3100, supporting the negative impact of CXCR4 on the chemo-sensitivity of lymphomas cells.

In this study, we observed higher CXCR4 in DLBCL exhibiting BM infiltration in a third independent DLBCL cohort, in line with previously published results [11,12]. It is known that CXCR4 is upregulated under hypoxic conditions in lymphoma [47] and several other cell lines [48-50] in vitro. Since the CXCR4-CXCL12-axis and hypoxic conditions have been linked to the BM metastasis of solid cancer [51-53] and based on xenograft experiments indicating a role for CXCR4 in bone marrow infiltration of DLBCL [10], it might be possible that this axis is also implicated in lymphoma progression and dissemination. The data on BM samples with or without involvement of DLBCL of our cohort showed a downregulation of CXCR4 in the BM of patients under remission after therapy as well as the correlation of the CXCL12 expression with lymphoma cell infiltration underpins this assumption.

Furthermore, we observed that AMD070 and its niacin derivative WK1 had pro-apoptotic effects in the CXCR4+ Burkitt lymphoma and one CXCR4+ GCB-DLBCL cell line as demonstrated by functional assays and gene expression analysis. In contrast, all cell lines (NGCB- and GCB-DLBCL), which were unaffected by the two treatments, were positive for CXCR4 and CXCR7. Moreover, a NGCB-DLBCL cell line, which was also unaffected by both treatments, was positive for CXCR4 only. The observed apoptotic properties of WK1 were even more pronounced compared to AMD070 as demonstrated by the induction of a higher number of pro-apoptotic genes and a higher percentage of apoptotic cells. In stark contrast, AMD3100 and niacin alone had no cytotoxic effects on the lymphoma cell lines. These findings are in line with already published data, where only the inhibition of migration of malignant and non-malignant cells for AMD3100 and growth inhibition for AMD070 have been reported [54,55]. However, our data indicate that the cytotoxic and/or apoptotic effects of AMD070 are increased by the addition of niacin and that these effects depend on the CXCR4 and CXCR7 expression patterns. Based on the gene expression analysis, which demonstrated that WK1 in particular induced more pro-apoptotic genes in a more pronounced manner, it seems that the type and/or subtype of lymphoma cell, especially GCB-DLBCL, may influence the induction of pro-apoptotic genes and response rates. However, based on the fact that AMD070 and WK1 (the two CXCR4 
antagonists possessing apoptotic effects) did not up- or downregulate the identical genes, it seems that the underlying molecular mechanism causing cell death is not mediated by the pro-apoptotic BCL2 family members. To the best of our knowledge, BKT140 was identified as the only CXCR4 antagonist possessing high cytotoxic/apoptotic properties in various solid cancer as well as lymphoma and leukemia cell lines so far $[24,56,57]$. Thus, WK1 represents a second molecule with the same effects as BKT140 and therefore could serve as a starting point for developing new compounds with anti-lymphoma activity.

Our explorative gene expression analysis of JNK-, ERK1/2-, and NF-KB/BCR-target genes demonstrated that three of five JNK targets, four of seven ERK1/2 target genes, and five of seven $\mathrm{NF}-\mathrm{KB} / \mathrm{BCR}$-targets were lower expressed in WK1 treated cells, whereas, the effects of AMD070 were diminished and for AMD3100 not detectable. Since JNK-, ERK1/2, and NF- $\mathrm{kB} / \mathrm{BCR}$ signaling plays an important role in the development of DLBCL [29-31], it could be speculated that the growth inhibitory effects of WK1 might also be mediated by the suppression of these ways.

In conclusion, our data indicate that the CXCR4-CXCL12-axis significantly contributes to the pathogenesis of aggressive lymphoma. The underlying mechanisms by which this axis influences the prognostic value may include lymphoma cell growth and dissemination, especially spreading to bone marrow. Based on the observed anti-lymphoma effects of the novel CXCR4 antagonist WK1, which is CXCR4-specific, the CXCR4-CXCL12-axis represents an interesting therapeutic target for CXCR4+ GCB-DLCBL at advanced disease stage and with potential BM infiltration.

\section{Materials and Methods}

\subsection{Patient Samples}

Our lymphoma cohort consisted of 71 histologically confirmed DLBCLs including 50 de novo and 21 transformed lymphoma samples (Table 2), receiving a Rituximab containing regimen at the Division of Hematology, Medical University of Graz between 2000 and 2010 (with last follow-up until May 2019). Examined transformed DLBCL samples with an underlying diagnosis of follicular lymphoma only contained the high-grade component. Clonal relationship between an initial FL sample and the resulting transformed DLBCL sample was determined by immunoglobulin heavy chain rearrangement PCR comparing the respectively paired specimens. All samples represented DLBCLs according to the WHO classification [58]. By using the Hans algorithm [5], all cases were classified as follows: 46 cases were categorized as GCB-DLBCL and 25 as NGCB-DLBCL. Determination of the IHC profiles according to the Hans algorithm has previously been described by Fechter et al. [59]. As transformed DLBCL samples originating from FLs exhibited a similar expression pattern as GCB-DLCBL samples [60], these samples were added to this subtype. For this retrospective study, we used patient specimens obtained for routine diagnostic procedures. Hence, no written informed consent of patients was obtained. The study was conducted in accordance with the Declaration of Helsinki, and the protocol was approved by the Ethics Committee of the Medical University Graz (No. 28-516/ex 15/16) on 3 October 2016.

In this study, germinal center B-cells were included as the non-neoplastic control and isolated from tonsils from young patients undergoing routine tonsillectomy as described in detail by our research group [61,62]. 
Table 2. Clinico-pathologic parameters of the lymphoma cohort.

\begin{tabular}{cccc}
\hline Clinico-Pathologic Parameters & Patients $(\boldsymbol{n}=\mathbf{7 1})$ & Proportion \\
\hline Subtype & NGCB & 25 & $35.2 \%$ \\
& GCB & 46 & $64.8 \%$ \\
\hline Sex & female & 37 & $52.11 \%$ \\
& male & 34 & $47.9 \%$ \\
\hline Age & $\leq 60 \mathrm{a}$ & 19 & $26.8 \%$ \\
& $>60 \mathrm{a}$ & 52 & $73.2 \%$ \\
\hline Stage & 1 & 16 & $20.5 \%$ \\
& 2 & 18 & $23.5 \%$ \\
& 3 & 26 & $34 \%$ \\
& 4 & 17 & $22 \%$ \\
\hline
\end{tabular}

\subsection{Sequencing of CXCR4}

Mutational profile by direct DNA sequencing of CXCR4 was carried out as previously described by our group [63]. In detail, PCR products were purified and sequenced from both sides using the BigDye terminator chemistry 3.1 (Applied Biosystems, Foster City, CA, USA). Sequences were run on an ABI3130-xl automated sequencer (Applied Biosystems, Foster City, CA, USA). For data analysis, the genebank file for CXCR4 (NG_011587.1) was used. The nucleotide acid sequences for the primer for these purposes are shown in Supplementary Table S2.

\subsection{Cell Lines and Cell Culture}

SuDHL4 as a model for GCB-DLBCL, RI-1, and U2932 as a model for NGCB-DLBCL and BL-2 as a model for Burkitt lymphomas, which is known to strongly express CXCR4 and migrate toward CXCL12 [24], were used for the in vitro experiments. SuDHL4, U2932, and RI-1 were cultured in suspension with Roswell Park Memorial Institute (RPMI) 1640 Medium (Gibco, Thermo Fisher Scientific, Waltham, MA, USA) supplemented with 10\% heat-inactivated fetal bovine serum (FBS) (Gibco, Thermo Fisher Scientific, Waltham, MA, USA) and 1\% Antibiotic-Antimycotic (Gibco, Thermo Fisher Scientific, Waltham, MA, USA). BL-2 cells were maintained in suspension in Roswell Park Memorial Institute (RPMI) 1640 Medium supplemented with 20\% FBS (Gibco, Thermo Fisher Scientific, Waltham, MA, USA) and 1\% Antibiotic-Antimycotic. Cells were periodically checked for mycoplasma by PCR and were found to be negative. The identity of the DLBCL cell lines was confirmed by variable number tandem repeats (VNTR) analysis using Power Plex 16 System (Promega, Madison, WI, USA), and verified at the online service of the DSMZ cell bank [64]. All cell lines were treated with the commercially available CXCR4 antagonists (MedChemExpress, Sollentuna, Sweden) AMD3100 and AMD070 [18], and the novel niacin derivative of AMD070 called WK1, which was generated by us, in a range from $1 \mu \mathrm{M}$ to $90 \mu \mathrm{M}$. Assays were carried out in triplicate wells and in at least two independent experiments.

\subsection{Synthesis of WK1}

AMD070 (MedChemExpress, Sollentuna, Sweden) (40 mg, $0.12 \mathrm{mmoL}, 1 \mathrm{eq}$ ) was dissolved in $\mathrm{MeOH}(800 \mu \mathrm{L})$. Nicotinyl chloride hydrochloride $(20.4 \mathrm{mg}, 0.12 \mathrm{mmoL}, 1 \mathrm{eq})$ and Et3N (32 $\mu \mathrm{L}$, $0.23 \mathrm{mmol}, 2 \mathrm{eq}$ ) were added and the reaction mixture was stirred at ambient temperature of $24 \mathrm{~h}$. After consumption of the starting material (detected by TLC: $\mathrm{CHCl}_{3} / \mathrm{MeOH} / \mathrm{concd}$. $\mathrm{NH}_{4} \mathrm{OH}=6 / 1 / 0.01$, $v / v / v)$ the reaction mixture was concentrated under reduced pressure and purified utilizing silica gel chromatography $\left(\mathrm{CHCl}_{3} / \mathrm{MeOH} / \mathrm{concd} . \mathrm{NH}_{4} \mathrm{OH}=20 / 1 / 0.01, v / v / v\right)$. WK $1(20 \mathrm{mg})$ was obtained as a colorless solid with a yield of $36 \%$. NMR-Spectra, Figure S10). 


\subsection{RNA Extraction and RQ-PCR}

Total RNA from fresh frozen DLBCL patient tissues, non-neoplastic germinal centre B cells, and lymphoma cell lines were isolated and cDNA synthesis was performed as previously described by our research group [61,62]. Real-time semi-quantitative PCR (RQ-PCR) for CXCR4, CXCR7, CXCL12, BAD, PUMA, BAX, BCL-XL, BCL-2, MCL1, BIK, BAK, BIM Iso 9, BID, BMF, NOXA, BCL2A1, CCL4, KLF10, OAS1, RGS1, TNF, EGR3, cFOS, BUB1, MXD1, JUNB, cJUN, ETV5, DUSP1, CCL22, CCR7, IL10, FN1, COL1A, CFLAR, and ADARB (Eurofins Genomic, Ebersberg, Germany and Qiagen, Hilden, Germany; assays and primers are listed in Table S2) was also performed as previously described [61,62]. GAPDH, $A C T B, P P I A$, and HPRT1, known to exhibit the lowest variability among lymphoid malignancies [65], were used as housekeeping genes and relative expression was calculated as described by us [61,62].

\subsection{Immunohistochemistry}

Formalin-fixed, paraffin-embedded tissue was pre-treated in a water bath with Target Retrieval Solution (1:10, Dako, Glostrup, Denmark) for $40 \mathrm{~min}$. Primary antibody to CXCR4 (1:200, order number: ab1640) was purchased from Abcam (Cambridge, UK) and primary antibody to CXCL12 (1:50, order number: MAB350) from R\&D Systems (Minneapolis, MN, USA). For staining, kit K5001 (Dako, Glostrup, Denmark) and the automated stainer intelliPATH FLX ${ }^{\circledR}$ (Biocare Medical, Pacheco, CA, USA) were used according to the manufacturer's instructions. We included tissues known to contain the respective antigens-reactive tonsils—as controls (positive controls). Replacing the primary antibody with normal serum always produced negative results (negative controls). Both negative and positive controls for CXCR4 and CXCL12 are shown in Figure S11a,b. DLBCL specimens were investigated regarding the staining intensities and percentages of the positive stained DLBCL cells according to the following procedure. For determination of the CXCR4 and CXCL12 expression, the whole section was screened for an equal distribution of positive cells. The determination of the percentage was done by calculating the average percentage of cytoplasmic NR4A1 positive cells in at least ten high-power-fields $\left(0.242 \mathrm{~mm}^{2}\right.$ each, field diameter: $555.1 \mu \mathrm{m})$. Percentages were rounded to $10 \%$.

\subsection{CXCL12 Binding Assay}

We used CXCL12 ${ }^{\mathrm{AF} 647}$ (ALMAC, Craigavon, UK) to determine the binding of CXCL12 to the CXCR4 and CXCR7 positive cells. First, either the CXCR4 antagonists AMD3100, AMD070 or WK1 to a final concentration between $0.01-20 \mu \mathrm{M}$ or blocking antibodies $(10 \mu \mathrm{g} / \mathrm{mL})$ targeting CXCR4 (clone: 9C4, MBL, Woburn, MA, USA), CXCR7 (clone: 11G8, ChemoCentryx Inc., Mountain View, CA, USA), or isotype controls were added to the cells and incubated for $45 \mathrm{~min}$ at $37^{\circ} \mathrm{C}$. The treated cells were further incubated with fluorescent CXCL12 ${ }^{\mathrm{AF} 647}(10 \mathrm{ng} / \mathrm{mL}$; BD Biosciences, San Jose, CA USA) for $3 \mathrm{~h}$ at $37^{\circ} \mathrm{C}$. Measurement was performed on the LSRII flow cytometer (Becton Dickinson, Franklin Lakes, NJ, USA) using CellQuest analysis software (Becton Dickinson, Franklin Lakes, NJ, USA).

\subsection{Assessment of Cell Growth}

Lymphoma cell lines were plated at a density of $10.000 / \mathrm{mL}$ in a 96-well plate and treated with CXCR4 antagonists AMD3100, AMD070, or WK1 in a range from $1 \mu \mathrm{M}$ to $90 \mu \mathrm{M}$. DMSO treated cells and pure medium served as controls and blanks. After treatment, cells were incubated for $72 \mathrm{~h}$ at $37^{\circ} \mathrm{C}$ and $5 \% \mathrm{CO}_{2}$. To measure cell proliferation and cytotoxicity, $20 \mu \mathrm{L}$ EZ4U reagent was added to each well and incubated for $4 \mathrm{~h}$ at $37^{\circ} \mathrm{C}$. Results were obtained by absorption measurement at $492 \mathrm{~nm}$ with an additional reference measurement at $620 \mathrm{~nm}$ using SpectroStar Photometer (BMG LABTECH, Ortenberg, Germany). All experiments were performed in triplicate and repeated at least twice.

\subsection{Apoptosis Assays}

Annexin V/7-AAD Staining: Cells were stained by using Annexin V/7-AAD kit (Biolegend, California, USA). Briefly, $200 \mu \mathrm{L}$ cell suspension was centrifuged and the supernatant was removed. The pellet was 
resuspended in $100 \mu \mathrm{L}$ Annexin V binding buffer (Biolegend, San Diego, CA, USA) and $5 \mu \mathrm{L}$ Annexin V-APC (BioLegend, San Diego, CA, USA) and 7-AAD (Biolegend, San Diego, CA, USA) were added, followed by incubation for $15 \mathrm{~min}$ at room temperature in the dark. Measurement was performed on the LSRII (Becton Dickinson, Franklin Lakes, NJ, USA) flow cytometer using CellQuest analysis software (Becton Dickinson, Franklin Lakes, NJ, USA).

To analyze caspase- 3 cleavage, cells were washed and then resuspended in $200 \mu \mathrm{L} 4 \%$ paraformaldehyde for $15 \mathrm{~min}$ at room temperature in the dark. Cells were permeabilized in methanol and incubated on ice for $30 \mathrm{~min}$. For immunostaining, cells were incubated for $1 \mathrm{~h}$ with Cleaved Caspase-3 rabbit mAb -AF647 (Cell Signaling, Cambridge, UK). Measurement was performed on the LSRII flow cytometer (Becton Dickinson, Franklin Lakes, NJ, USA) using CellQuest analysis software (Becton Dickinson, Franklin Lakes, NJ, USA).

\subsection{Migration Assay}

Migration assays were performed using Transwell ${ }^{\circledR}$ inserts (Costar, $6.5 \mathrm{~mm}$ diameter, polycarbonate membrane with $5.0 \mu \mathrm{M}$ pores). Briefly, $3 \times 10^{5}$ cells were resuspended in $100 \mu \mathrm{L}$ RPMI 1640 medium containing $5 \%$ serum and pre-treated with vehicle or $1 \mu \mathrm{M}$ of the CXCR4 antagonists AMD70 and WK1 at $37^{\circ} \mathrm{C}$ for $2 \mathrm{~h}$. Subsequently, cells were transferred onto the Transwell ${ }^{\circledR}$ inserts and placed into 24-well trays. The lower compartment was filled with $600 \mu \mathrm{L}$ RPMI 1640 medium with $5 \%$ serum-containing $100 \mathrm{ng} / \mathrm{mL}$ CXCL12 agonists (AMD070 and WK1) or vehicle. Cells were allowed to migrate for $18 \mathrm{~h}$ at $37^{\circ} \mathrm{C}$ in a humidified atmosphere and $5 \% \mathrm{CO}_{2}$. The number of cells migrating to the lower compartment was quantified by flow cytometry. Results are shown as means \pm SEMs of $n=3-4$ independent experiments and are expressed as $\%$ of control response.

\subsection{Microarray Analysis}

The E-GEOD-10846 dataset (Affymetrix GeneChip Human Genome U133 Plus 2.0) [20] was download from ArrayExpress and analyzed in R 3.5.1 [66]. By applying rma, the data were preprocessed with the R package 'oligo' [67]. Only samples of patients $(n=200)$ who were treated with RCHOP or were assigned a subtype diagnosis were included for further analysis. Expression values for the probe set annotated as CXCR4 were extracted.

\subsection{Statistical Analysis}

For statistical analysis, IBM SPSS Statistics for Windows, Version 23.0 (IBM Corp., New York, USA) was used. $p$-values $<0.05$ were considered statistically significant. The Shapiro-Wilk test was used to test for normality of distribution. Depending on the test result, a t-test or a Mann-Whitney U-test, its non-parametric counterpart, was used to investigate mRNA expression for differences (two-sided $p$-value). 5-year-survival was defined as the time in months from the date of diagnosis to death by any cause.

Survival analysis was performed in R 3.5.1 [66] using the R package 'survival' [68] and 'survminer' [69]. The patients were split into low- and high-expression groups by using the third quartile of CXCR4, CXCL12 and CXCR7 expression. Survival was calculated with the Kaplan-Meier method and compared by the log-rank test.

Supplementary Materials: Supplementary materials can be found at http:/www.mdpi.com/1422-0067/20/19/4740/s1.

Author Contributions: K.P. performed most of the experiments with the support of B.E., B.P., and K.F. and also analyzed the acquired data together with J.F. J.F. performed the statistical analysis and the analysis of public available gene expression data together with G.G.T. K.T.P., B.U., A.W., and P.N. collected clinical data and were implicated in the interpretation of the data and study design. E.S. and V.G. performed IHC staining. D.R., M.S., and A.H. performed the migration assays. M.Z. and T.M.W. synthesized WK1. C.B.-S. performed IHC analysis. H.T.G. provided lab space and was implicated in the study design. A.J.D. designed the whole project and wrote the manuscript together with K.P. and K.F. 
Funding: K.F. was supported by a grant from the Austrian Society of Hematology and Oncology (ASHO research grant). J.F. was supported by a grant from the OMICS Center Graz of the Austrian Ministry of Science, Research and Economy (to GGT) and the Austrian Science Fund (FWF): T923-B26. A.J.D. was supported by the START-Funding-Program of the Medical University of Graz, by a research grant of the MEFOgraz, and by research grants from the OeGHO (clinical, translational, and ASHO research grant).

Acknowledgments: The authors especially thank the Doctoral Program of Medical Science, Medical University of Graz, Austria. The authors especially thank the Open Access Funding by the Austrian Science Fund (FWF).

Conflicts of Interest: The authors declare no conflict of interest.

\section{References}

1. Pasqualucci, L.; Dalla-Favera, R. The genetic landscape of diffuse large B-cell lymphoma. Semin. Hematol. 2015, 52, 67-76. [CrossRef] [PubMed]

2. Bouska, A.; McKeithan, T.W.; Deffenbacher, K.E.; Lachel, C.; Wright, G.W.; Iqbal, J.; Smith, L.M.; Zhang, W.; Kucuk, C.; Rinaldi, A.; et al. Genome-wide copy-number analyses reveal genomic abnormalities involved in transformation of follicular lymphoma. Blood 2014, 123, 1681-1690. [CrossRef] [PubMed]

3. de Jong, D.; Balagué Ponz, O. The molecular background of aggressive B cell lymphomas as a basis for targeted therapy. J. Pathol. 2011, 223, 274-282. [CrossRef] [PubMed]

4. Lenz, G.; Staudt, L.M. Aggressive lymphomas. N. Engl. J. Med. 2010, 362, 1417-1429. [CrossRef] [PubMed]

5. Hans, C.P.; Weisenburger, D.D.; Greiner, T.C.; Gascoyne, R.D.; Delabie, J.; Ott, G.; Müller-Hermelink, H.K.; Campo, E.; Braziel, R.M.; Jaffe, E.S.; et al. Confirmation of the molecular classification of diffuse large B-cell lymphoma by immunohistochemistry using a tissue microarray. Blood 2004, 103, 275-282. [CrossRef] [PubMed]

6. D’Apuzzo, M.; Rolink, A.; Loetscher, M.; Hoxie, J.A.; Clark-Lewis, I.; Melchers, F.; Baggiolini, M.; Moser, B. The chemokine SDF-1, stromal cell-derived factor 1, attracts early stage B cell precursors via the chemokine receptor CXCR4. Eur. J. Immunol. 1997, 27, 1788-1793. [CrossRef] [PubMed]

7. Egawa, T.; Kawabata, K.; Kawamoto, H.; Amada, K.; Okamoto, R.; Fujii, N.; Kishimoto, T.; Katsura, Y.; Nagasawa, T. The earliest stages of B cell development require a chemokine stromal cell-derived factor/pre-B cell growth-stimulating factor. Immunity 2001, 15, 323-334. [CrossRef]

8. Nie, Y.; Waite, J.; Brewer, F.; Sunshine, M.-J.; Littman, D.R.; Zou, Y.-R. The role of CXCR4 in maintaining peripheral B cell compartments and humoral immunity. J. Exp. Med. 2004, 200, 1145-1156. [CrossRef] [PubMed]

9. Okada, T.; Ngo, V.N.; Ekland, E.H.; Förster, R.; Lipp, M.; Littman, D.R.; Cyster, J.G. Chemokine requirements for B cell entry to lymph nodes and Peyer's patches. J. Exp. Med. 2002, 196, 65-75. [CrossRef] [PubMed]

10. Chen, J.; Xu-Monette, Z.Y.; Deng, L.; Shen, Q.; Manyam, G.C.; Martinez-Lopez, A.; Zhang, L.; Montes-Moreno, S.; Visco, C.; Tzankov, A.; et al. Dysregulated CXCR4 expression promotes lymphoma cell survival and independently predicts disease progression in germinal center B-cell-like diffuse large B-cell lymphoma. Oncotarget 2015, 6, 5597-5614. [CrossRef]

11. Deutsch, A.J.A.; Steinbauer, E.; Hofmann, N.A.; Strunk, D.; Gerlza, T.; Beham-Schmid, C.; Schaider, H.; Neumeister, P. Chemokine receptors in gastric MALT lymphoma: loss of CXCR4 and upregulation of CXCR7 is associated with progression to diffuse large B-cell lymphoma. Mod. Pathol. 2013, 26, 182-194. [CrossRef] [PubMed]

12. Du, H.; Zhang, L.; Li, G.; Liu, W.; Tang, W.; Zhang, H.; Luan, J.; Gao, L.; Wang, X. CXCR4 and CCR7 Expression in Primary Nodal Diffuse Large B-Cell Lymphoma-A Clinical and Immunohistochemical Study. Am. J. Med. Sci. 2019, 357, 302-310. [CrossRef] [PubMed]

13. Laursen, M.B.; Reinholdt, L.; Schönherz, A.A.; Due, H.; Jespersen, D.S.; Grubach, L.; Ettrup, M.S.; Røge, R.; Falgreen, S.; Sørensen, S.; et al. High CXCR4 expression impairs rituximab response and the prognosis of R-CHOP-treated diffuse large B-cell lymphoma patients. Oncotarget 2019, 10, 717-731. [CrossRef] [PubMed]

14. Moreno, M.J.; Bosch, R.; Dieguez-Gonzalez, R.; Novelli, S.; Mozos, A.; Gallardo, A.; Pavón, M.Á.; Céspedes, M.V.; Grañena, A.; Alcoceba, M.; et al. CXCR4 expression enhances diffuse large B cell lymphoma dissemination and decreases patient survival. J. Pathol. 2015, 235, 445-455. [CrossRef] [PubMed]

15. Shin, H.C.; Seo, J.; Kang, B.W.; Moon, J.H.; Chae, Y.S.; Lee, S.J.; Lee, Y.J.; Han, S.; Seo, S.K.; Kim, J.G.; et al. Clinical significance of nuclear factor $\mathrm{\kappa B}$ and chemokine receptor CXCR4 expression in patients with diffuse 
large B-cell lymphoma who received rituximab-based therapy. Korean J. Intern. Med. 2014, 29, 785-792. [CrossRef] [PubMed]

16. Xu, Z.-Z.; Shen, J.-K.; Zhao, S.-Q.; Li, J.-M. Clinical significance of chemokine receptor CXCR4 and mammalian target of rapamycin (mTOR) expression in patients with diffuse large B-cell lymphoma. Leuk. Lymphoma 2018, 59, 1451-1460. [CrossRef] [PubMed]

17. Balabanian, K.; Lagane, B.; Infantino, S.; Chow, K.Y.C.; Harriague, J.; Moepps, B.; Arenzana-Seisdedos, F.; Thelen, M.; Bachelerie, F. The chemokine SDF-1/CXCL12 binds to and signals through the orphan receptor RDC1 in T lymphocytes. J. Biol. Chem. 2005, 280, 35760-35766. [CrossRef] [PubMed]

18. Debnath, B.; Xu, S.; Grande, F.; Garofalo, A.; Neamati, N. Small molecule inhibitors of CXCR4. Theranostics 2013, 3, 47-75. [CrossRef]

19. Shakir, M.; Tang, D.; Zeh, H.J.; Tang, S.W.; Anderson, C.J.; Bahary, N.; Lotze, M.T. The chemokine receptors CXCR4/CXCR7 and their primary heterodimeric ligands CXCL12 and CXCL12/high mobility group box 1 in pancreatic cancer growth and development: finding flow. Pancreas 2015, 44, 528-534. [CrossRef]

20. Lenz, G.; Wright, G.; Dave, S.S.; Xiao, W.; Powell, J.; Zhao, H.; Xu, W.; Tan, B.; Goldschmidt, N.; Iqbal, J.; et al. Stromal gene signatures in large-B-cell lymphomas. N. Engl. J. Med. 2008, 359, 2313-2323. [CrossRef]

21. Hunter, Z.R.; Xu, L.; Yang, G.; Zhou, Y.; Liu, X.; Cao, Y.; Manning, R.J.; Tripsas, C.; Patterson, C.J.; Sheehy, P.; et al. The genomic landscape of Waldenstrom macroglobulinemia is characterized by highly recurring MYD88 and WHIM-like CXCR4 mutations, and small somatic deletions associated with B-cell lymphomagenesis. Blood 2014, 123, 1637-1646. [CrossRef] [PubMed]

22. Treon, S.P.; Cao, Y.; Xu, L.; Yang, G.; Liu, X.; Hunter, Z.R. Somatic mutations in MYD88 and CXCR4 are determinants of clinical presentation and overall survival in Waldenstrom macroglobulinemia. Blood 2014, 123, 2791-2796. [CrossRef] [PubMed]

23. Home-SNP-NCBI. Available online: https://www.ncbi.nlm.nih.gov/snp/ (accessed on 23 September 2019).

24. Beider, K.; Ribakovsky, E.; Abraham, M.; Wald, H.; Weiss, L.; Rosenberg, E.; Galun, E.; Avigdor, A.; Eizenberg, O.; Peled, A.; et al. Targeting the CD20 and CXCR4 pathways in non-hodgkin lymphoma with rituximab and high-affinity CXCR4 antagonist BKT140. Clin. Cancer Res. 2013, 19, 3495-3507. [CrossRef] [PubMed]

25. Amini, R.-M.; Berglund, M.; Rosenquist, R.; von Heideman, A.; Lagercrantz, S.; Thunberg, U.; Bergh, J.; Sundström, C.; Glimelius, B.; Enblad, G. A Novel B-cell Line (U-2932) Established from a Patient with Diffuse Large B-cell Lymphoma Following Hodgkin Lymphoma. Leuk. Lymphoma 2002, 43, 2179-2189. [CrossRef] [PubMed]

26. Klanova, M.; Andera, L.; Brazina, J.; Svadlenka, J.; Benesova, S.; Soukup, J.; Prukova, D.; Vejmelkova, D.; Jaksa, R.; Helman, K.; et al. Targeting of BCL2 Family Proteins with ABT-199 and Homoharringtonine Reveals BCL2- and MCL1-Dependent Subgroups of Diffuse Large B-Cell Lymphoma. Clin. Cancer Res. 2016, 22, 1138-1149. [CrossRef] [PubMed]

27. Masir, N.; Campbell, L.J.; Jones, M.; Mason, D.Y. Pseudonegative BCL2 protein expression in a $t(14 ; 18)$ translocation positive lymphoma cell line: a need for an alternative BCL2 antibody. Pathology 2010, 42, 212-216. [CrossRef] [PubMed]

28. Finke, J.; Fritzen, R.; Ternes, P.; Trivedi, P.; Bross, K.J.; Lange, W.; Mertelsmann, R.; Dolken, G. Expression of bcl-2 in Burkitt's lymphoma cell lines: induction by latent Epstein-Barr virus genes. Blood 1992, 80, 459.

29. Young, R.M.; Shaffer, A.L.; Phelan, J.D.; Staudt, L.M. B-cell receptor signaling in diffuse large B-cell lymphoma. Semin. Hematol. 2015, 52, 77-85. [CrossRef]

30. Dai, B.; Zhao, X.F.; Mazan-Mamczarz, K.; Hagner, P.; Corl, S.; Bahassi, E.M.; Lu, S.; Stambrook, P.J.; Shapiro, P.; Gartenhaus, R.B. Functional and molecular interactions between ERK and CHK2 in diffuse large B-cell lymphoma. Nat. Commun. 2011, 2, 402. [CrossRef]

31. Tian, X.; Pelton, A.; Shahsafaei, A.; Dorfman, D.M. Differential expression of enhancer of zeste homolog 2 (EZH2) protein in small cell and aggressive B-cell non-Hodgkin lymphomas and differential regulation of EZH2 expression by p-ERK1/2 and MYC in aggressive B-cell lymphomas. Mod. Pathol. 2016, 29, 1050-1057. [CrossRef]

32. Nguyen, T.K.; Jordan, N.; Friedberg, J.; Fisher, R.I.; Dent, P.; Grant, S. Inhibition of MEK/ERK1/2 sensitizes lymphoma cells to sorafenib-induced apoptosis. Leuk. Res. 2010, 34, 379-386. [CrossRef] [PubMed] 
33. Schmid, C.A.; Robinson, M.D.; Scheifinger, N.A.; Müller, S.; Cogliatti, S.; Tzankov, A.; Müller, A. DUSP4 deficiency caused by promoter hypermethylation drives JNK signaling and tumor cell survival in diffuse large B cell lymphoma. J. Exp. Med. 2015, 212, 775-792. [CrossRef] [PubMed]

34. Grill, C.; Gheyas, F.; Dayananth, P.; Jin, W.; Ding, W.; Qiu, P.; Wang, L.; Doll, R.J.; English, J.M. Analysis of the ERK1,2 transcriptome in mammary epithelial cells. Biochem. J. 2004, 381, 635-644. [CrossRef] [PubMed]

35. Herman, S.E.M.; Mustafa, R.Z.; Gyamfi, J.A.; Pittaluga, S.; Chang, S.; Chang, B.; Farooqui, M.; Wiestner, A. Ibrutinib inhibits BCR and NF- $\mathrm{B}$ s signaling and reduces tumor proliferation in tissue-resident cells of patients with CLL. Blood 2014, 123, 3286-3295. [CrossRef] [PubMed]

36. Stein, J.V.; Nombela-Arrieta, C. Chemokine control of lymphocyte trafficking: a general overview. Immunology 2005, 116, 1-12. [CrossRef] [PubMed]

37. Cojoc, M.; Peitzsch, C.; Trautmann, F.; Polishchuk, L.; Telegeev, G.D.; Dubrovska, A. Emerging targets in cancer management: role of the CXCL12/CXCR4 axis. OncoTargets Ther. 2013, 6, 1347-1361. [CrossRef]

38. Sun, X.; Cheng, G.; Hao, M.; Zheng, J.; Zhou, X.; Zhang, J.; Taichman, R.S.; Pienta, K.J.; Wang, J. CXCL12/CXCR4/CXCR7 chemokine axis and cancer progression. Cancer Metastasis Rev. 2010, 29, 709-722. [CrossRef] [PubMed]

39. Gangadhar, T.; Nandi, S.; Salgia, R. The role of chemokine receptor CXCR4 in lung cancer. Cancer Biol. Ther. 2010, 9, 409-416. [CrossRef]

40. Weber, T.S. Cell Cycle-Associated CXCR4 Expression in Germinal Center B Cells and Its Implications on Affinity Maturation. Front. Immunol. 2018, 9, 1313. [CrossRef]

41. Casulo, C.; Burack, W.R.; Friedberg, J.W. Transformed follicular non-Hodgkin lymphoma. Blood 2015, 125, 40-47. [CrossRef]

42. Moreno, M.J.; Gallardo, A.; Novelli, S.; Mozos, A.; Aragó, M.; Pavón, M.Á.; Céspedes, M.V.; Pallarès, V.; Falgàs, A.; Alcoceba, M.; et al. CXCR7 expression in diffuse large B-cell lymphoma identifies a subgroup of CXCR4+ patients with good prognosis. PLoS ONE 2018, 13, e0198789. [CrossRef] [PubMed]

43. Döring, Y.; Pawig, L.; Weber, C.; Noels, H. The CXCL12/CXCR4 chemokine ligand/receptor axis in cardiovascular disease. Front. Physiol. 2014, 5, 212. [CrossRef] [PubMed]

44. Du, H.; Gao, L.; Luan, J.; Zhang, H.; Xiao, T. C-X-C Chemokine Receptor 4 in Diffuse Large B Cell Lymphoma: Achievements and Challenges. Acta Haematol. 2019, 1-7. [CrossRef] [PubMed]

45. Zhou, W.; Guo, S.; Liu, M.; Burow, M.E.; Wang, G. Targeting CXCL12/CXCR4 Axis in Tumor Immunotherapy. Curr. Med. Chem. 2017. [CrossRef] [PubMed]

46. Sehn, L.H.; Donaldson, J.; Chhanabhai, M.; Fitzgerald, C.; Gill, K.; Klasa, R.; MacPherson, N.; O’Reilly, S.; Spinelli, J.J.; Sutherland, J.; et al. Introduction of Combined CHOP Plus Rituximab Therapy Dramatically Improved Outcome of Diffuse Large B-Cell Lymphoma in British Columbia. JCO 2005, 23, 5027-5033. [CrossRef] [PubMed]

47. Piovan, E.; Tosello, V.; Indraccolo, S.; Masiero, M.; Persano, L.; Esposito, G.; Zamarchi, R.; Ponzoni, M.; Chieco-Bianchi, L.; Dalla-Favera, R.; et al. Differential regulation of hypoxia-induced CXCR4 triggering during B-cell development and lymphomagenesis. Cancer Res. 2007, 67, 8605-8614. [CrossRef] [PubMed]

48. Oh, Y.S.; Kim, H.Y.; Song, I.-C.; Yun, H.-J.; Jo, D.-Y.; Kim, S.; Lee, H.J. Hypoxia induces CXCR4 expression and biological activity in gastric cancer cells through activation of hypoxia-inducible factor-1 $\alpha$. Oncol. Rep. 2012, 28, 2239-2246. [CrossRef] [PubMed]

49. Guo, M.; Cai, C.; Zhao, G.; Qiu, X.; Zhao, H.; Ma, Q.; Tian, L.; Li, X.; Hu, Y.; Liao, B.; et al. Hypoxia promotes migration and induces CXCR4 expression via HIF-1 $\alpha$ activation in human osteosarcoma. PLoS ONE 2014, 9, e90518. [CrossRef]

50. Schioppa, T.; Uranchimeg, B.; Saccani, A.; Biswas, S.K.; Doni, A.; Rapisarda, A.; Bernasconi, S.; Saccani, S.; Nebuloni, M.; Vago, L.; et al. Regulation of the chemokine receptor CXCR4 by hypoxia. J. Exp. Med. 2003, 198, 1391-1402. [CrossRef]

51. Chatterjee, S.; Behnam Azad, B.; Nimmagadda, S. The intricate role of CXCR4 in cancer. Adv. Cancer Res. 2014, 124, 31-82. [CrossRef]

52. Hiraga, T. Hypoxic Microenvironment and Metastatic Bone Disease. Int. J. Mol. Sci. 2018, 19, 3523. [CrossRef] [PubMed]

53. Shi, J.; Wei, Y.; Xia, J.; Wang, S.; Wu, J.; Chen, F.; Huang, G.; Chen, J. CXCL12-CXCR4 contributes to the implication of bone marrow in cancer metastasis. Future Oncol. 2014, 10, 749-759. [CrossRef] [PubMed] 
54. de Clercq, E. Recent advances on the use of the CXCR4 antagonist plerixafor (AMD3100, Mozobil ${ }^{\mathrm{TM}}$ ) and potential of other CXCR4 antagonists as stem cell mobilizers. Pharmacol. Ther. 2010, 128, 509-518. [CrossRef] [PubMed]

55. Uchida, D.; Kuribayashi, N.; Kinouchi, M.; Sawatani, Y.; Shimura, M.; Mori, T.; Hasegawa, T.; Miyamoto, Y.; Kawamata, H. Effect of a novel orally bioavailable CXCR4 inhibitor, AMD070, on the metastasis of oral cancer cells. Oncol. Rep. 2018, 40, 303-308. [CrossRef] [PubMed]

56. Beider, K.; Darash-Yahana, M.; Blaier, O.; Koren-Michowitz, M.; Abraham, M.; Wald, H.; Wald, O.; Galun, E.; Eizenberg, O.; Peled, A.; et al. Combination of imatinib with CXCR4 antagonist BKT140 overcomes the protective effect of stroma and targets CML in vitro and in vivo. Mol. Cancer Ther. 2014, 13, 1155-1169. [CrossRef] [PubMed]

57. Fahham, D.; Weiss, I.D.; Abraham, M.; Beider, K.; Hanna, W.; Shlomai, Z.; Eizenberg, O.; Zamir, G.; Izhar, U.; Shapira, O.M.; et al. In vitro and in vivo therapeutic efficacy of CXCR4 antagonist BKT140 against human non-small cell lung cancer. J. Thorac. Cardiovasc. Surg. 2012, 144, 1167-1175.e1. [CrossRef] [PubMed]

58. Swerdlow, S.H.; Campo, E.; Harris, N.L.; Jaffe, E.S.; Pileri, S.A.; Stein, H.; Thiele, J. (Eds.) WHO classification of tumours of haematopoietic and lymphoid tissues, Revised 4th ed.; International Agency for Research on Cancer: Lyon, France, 2017; ISBN 928324494X.

59. Fechter, K.; Feichtinger, J.; Prochazka, K.; Unterluggauer, J.J.; Pansy, K.; Steinbauer, E.; Pichler, M.; Haybaeck, J.; Prokesch, A.; Greinix, H.T.; et al. Cytoplasmic location of NR4A1 in aggressive lymphomas is associated with a favourable cancer specific survival. Sci. Rep. 2018, 8. [CrossRef] [PubMed]

60. Davies, A.J.; Rosenwald, A.; Wright, G.; Lee, A.; Last, K.W.; Weisenburger, D.D.; Chan, W.C.; Delabie, J.; Braziel, R.M.; Campo, E.; et al. Transformation of follicular lymphoma to diffuse large B-cell lymphoma proceeds by distinct oncogenic mechanisms. Br. J. Haematol. 2007, 136, 286-293. [CrossRef] [PubMed]

61. Deutsch, A.J.A.; Rinner, B.; Pichler, M.; Prochazka, K.; Pansy, K.; Bischof, M.; Fechter, K.; Hatzl, S.; Feichtinger, J.; Wenzl, K.; et al. NR4A3 Suppresses Lymphomagenesis through Induction of Proapoptotic Genes. Cancer Res. 2017, 77, 2375-2386. [CrossRef] [PubMed]

62. Deutsch, A.J.A.; Rinner, B.; Wenzl, K.; Pichler, M.; Troppan, K.; Steinbauer, E.; Schwarzenbacher, D.; Reitter, S.; Feichtinger, J.; Tierling, S.; et al. NR4A1-mediated apoptosis suppresses lymphomagenesis and is associated with a favorable cancer-specific survival in patients with aggressive B-cell lymphomas. Blood 2014, 123, 2367-2377. [CrossRef] [PubMed]

63. Deutsch, A.J.A.; Aigelsreiter, A.; Staber, P.B.; Beham, A.; Linkesch, W.; Guelly, C.; Brezinschek, R.I.; Fruhwirth, M.; Emberger, W.; Buettner, M.; et al. MALT lymphoma and extranodal diffuse large B-cell lymphoma are targeted by aberrant somatic hypermutation. Blood 2007, 109, 3500-3504. [CrossRef] [PubMed]

64. German Collection of Microorganisms and Cell Cultures GmbH: Welcome to the Leibniz Institute DSMZ. Available online: https://www.dsmz.de/ (accessed on 23 September 2019).

65. Lossos, I.S.; Levy, R. Diffuse large B-cell lymphoma: insights gained from gene expression profiling. Int. J. Hematol. 2003, 77, 321-329. [CrossRef] [PubMed]

66. R Core Team. R: A Language and Environment for Statistical Computing; R Foundation for Statistical Computing: Vienna, Austria, 2018; Available online: https://www.R-project.org/ (accessed on 24 September 2019).

67. Carvalho, B.S.; Irizarry, R.A. A framework for oligonucleotide microarray preprocessing. Bioinformatics 2010, 26, 2363-2367. [CrossRef] [PubMed]

68. Therneau, T.M.; Grambsch, P.M. Modeling Survival Data: Extending the Cox Model; Springer: New York, NY, USA, 2000; p. xiii + 350. ISBN 0-387-98784-3.

69. Kassambara, A.; Kosinski, M. Drawing Survival Curves using 'ggplot2'. Available online: https://cran.rproject.org/web/packages/survminer/survminer.pdf (accessed on 3 September 2019).

(C) 2019 by the authors. Licensee MDPI, Basel, Switzerland. This article is an open access article distributed under the terms and conditions of the Creative Commons Attribution (CC BY) license (http://creativecommons.org/licenses/by/4.0/). 